\title{
E-Commerce Security in Rural Tourism based on Factor Analysis
}

\author{
Hui Song ${ }^{1,2}$ and Ling $\mathrm{Wu}^{1,2, *}$ \\ ${ }^{1}$ School of Management Engineering, Suzhou University, \\ Suzhou city, Anhui province, \\ 234000, China \\ ${ }^{2}$ Research Center of Northern Anhui Urban-rural Integration \\ songhuisuzhou@163.com
}

\begin{abstract}
The current third-party network service in B2C business is not perfect in China, rural tourism enterprises frequent change the third-party platform because the cooperation risk. The rural tourism industry is developing fast; however, most tourism enterprises are not clear whether third-party network platform will increase the economic and social value by cooperation. Also, the third-party platform is not effective to improve the business level, and do not know how to improve the service quality. Therefore, the thirdparty platform should pay more attention to the service quality and perceived value, grasp the collaborative operation of cognition, improve the cooperation performance by increasing relationship quality, and promote to establish a solid and long-term cooperation relationship.
\end{abstract}

Keywords: Cooperation Risk; Rural tourism industry; Third-party network platform; Confirmatory factor Analysis

\section{Introduction}

At present, the rapid rise in rural tourism service was shown in the electronic commerce market. The survey from Chinese industrial and commercial bureau show that, in 2013, total business volume of tourism service enterprises which has a certain scale has completed reached 3.87 billion, added $32.9 \%$ more than the volume of business in 2012. As of the end of 2013, more than seven thousand tourism service enterprises have obtained the business license, an increase of 1200 enterprises than last year. Also, the business outlets of tourism service enterprises extended to 70 thousand, related employees as 730 thousand people. In the future, the role of multiple factors of enterprise development and market demand, the policy, the domestic express enterprises will accelerate the pace of merger and reorganization; the launch of the listing process, the foreign capital company will enter the domestic express market. Tourism service enterprises in the market competition will be more intense, from traditional price competition to focus on improving the transformation of value-added services and service commitments in region, to achieve industrial agglomeration, intensive management and the function [1]. In the actual operation process of the tourism service enterprises, standardization of operation, management concept and resource adequacy is different. The interchangeability in most tourism service enterprises is strong, only a small part of the enterprise who focus on cooperation performance that will establish long-term cooperative relations between $\mathrm{B} 2 \mathrm{C}$ enterprises [2].Therefore, B2C e-commerce enterprises should make better use of social resources, so the factors that will influence cooperative performance needed to be further researched, and researchers should provide practical suggestion for the tourism service enterprises. 
Domestic and foreign scholars mainly research on the cooperation between tourism enterprises and e-commerce platform the following aspects: 1. tourism enterprise will choose the self built platform or third-party service platform according to their own conditions [3]; 2. Evaluation the business performance in third-party service platform; 3. The scope of cooperation between the E-business platform and the tourism service enterprises, including the payment, inventory management, customer service, application of information activities and order processing, participate in the planning. However, there is few articles research on the influencing factors of the cooperation between the between the tourism enterprise and the third-party service platform.

The reason of enterprises' cooperation is usually considered as the market competition, this competition or change will incentive enterprises to build alliances or industrial cluster [4]. Vertically integrated companies in supply chain tend to cooperation and expand the market jointly, then share the benefit form the scale economy profit. With the deepening of cooperation, how to avoid misunderstanding and unnecessary friction becomes the focus to improve the cooperation performance [5]. There are also some scholars pointed out that the cooperation intention, trust and commitment will have significant impact on long-term cooperative relationship [6]. According to the theory of relationship quality, the experts mainly emphasizes the influence degree of relationship quality on cooperative performance, usually the two sides cooperative enterprises to establish a good trust, close communication, have the intention and behavior loyalty, then this will have a positive effect on cooperative performance. In the supply chain research field, all enterprises establish a good relationship quality and upstream and downstream enterprises; this is the key elements to success in the fierce competition [7]. Among them, trust, agreed and benefit sharing is the key to achieve business success. Most scholars have researched the relationship quality from different perspective, but there is little research about the effect mechanism. In this paper, we try to find out the factors that will influence relationship quality in the actual process of cooperation.

\section{Literature Review}

\subsection{E-commerce and Third Party Platform}

The service object of B2C E-business is the enterprise and individual, tool is information technology services, business support services and the internet trading service, electronic commerce is a new kind of commercial operation mode that catering to the era of science and technology development. B2C electronic commerce refers to the network just for personal marketing activities, has the characteristics of low transaction amount, high transaction frequency [8]. With the popularity of the network, users can purchase and browse products at any time, this also emphasize the interactive between $\mathrm{B} 2 \mathrm{C}$ business enterprise and customer. Marketing activities must attract people and goods need get the recognition and praise, so that $\mathrm{B} 2 \mathrm{C}$ companies should develop personalized service standards, strengthen dialogue and communication [9].

The concept of third-party platform refers to a kind of the service outsourcing business; outsourcing means that enterprises allocate internal and external resources, services and function flexibly, in order to realize the value maximization [10]. Service outsourcing including goods delivery, payment collection, warehousing management, inventory management, information activities and order processing, etc. 


\subsection{Perceptive Value in Cooperation}

Perceived value includes four aspects: low price, obtain the actual utility, tradeoff between price and quality, comparison between gains and losses. Sweeney (1999) pointed out that customer perceived effect is based on the comparison between payment and reward; it is the overall evaluation of the goods and services. In addition, Derbaix( 1985) thinks the service effectiveness is the basis of customer perceived value. In economics research, usually assume that information is full and transparent, all individual participating in the economic activities are rational and can make rational judgment and choice, but in real life, consumers only have limited rationality. In addition, the personal consumption experience is an important basis for the evaluation of the value of goods or services. Customer evaluation is differing from man to man, at the same time; it will change with time and location. In the process of cooperation, the customer from the first time purchase then develop to long-term customers, their evaluation criteria will become mature, objective, comprehensive. We learn from the cooperation frame model to illustrate the business enterprise and third party logistics cooperation. The impact refers to economic benefits and promotion from cooperation; intimacy refers to diffusion and deepening in the cooperation scope; vision refers to the enterprises have a common goal, these factors have great effect in promoting the establishment of strategic alliance

\section{Data Collection and Model Design}

\subsection{Questionnaire Design}

According to previous research on the questionnaire survey, the design thought of this questionnaire is divided into five steps: (1) design several categories according to the existing literature and research; (2) integrate literature and refine each category ;(3)assume the logical relationship existing between variables, then set up related issues;(4) using expert interviews, adoption their opinions and suggestions, then improve the questionnaire; (5) determine the measurement problem for each variable by exploratory factor analysis, and determine the final questionnaire. The idea of questionnaire design come from arranging and analyzing previous literature, it refers to enterprise cooperation between third-party logistics and the B2C business enterprise. We obtains the preliminary questionnaire by summarizing and comparing existing results, then use expert interviews to increase the appropriateness of the questionnaire items.

In order to improve the questionnaire as simple and effective, we will release a part of the pretest questionnaire, through the screening of the results to determine the final items. Finally, we will release a lot of formal questionnaire and collect data, then make reliability test, validity test, correlation analysis and regression analysis by using SPSS software.

\subsection{Variable Description}

The independent variables is relationship perception, there are four primary indicators of relationship perception as "the hardware facilities in the third-party network platform", "the service quality that the third-party network platform provided", "the expected contribution of the third-party network platform" and "perceived risk of B2C electric business". The intermediary variables is relationship quality, it include four primary indicators as "Trust", "Communication", "Behavioral loyalty" and "Intentionality loyalty". The dependent variable is cooperation performance, it include two primary indicators as "economic value" and "social value" from the third-party network platform. The primary indicators and the 
description of secondary indicators were shown below. The moderator variable is the external environment, it include two primary indicators as "The result quality of cooperation" and "Social psychological risk". All indicators was shown in table 1.

\section{Table 1. Description of Primary Indicators}

\begin{tabular}{|l|l|}
\hline Code & Variable description \\
\hline$\alpha 1$ & The hardware facilities in Third-party network platform \\
\hline$\alpha 2$ & The service quality that third-party network platform provided \\
\hline$\alpha 3$ & The expected contribution of third-party network platform \\
\hline$\alpha 4$ & Perceived risk of B2C electric business \\
\hline$\alpha 5$ & Trust with B2C electric enterprise \\
\hline$\alpha 6$ & Communication with B2C electric enterprise \\
\hline$\alpha 7$ & Intentionality loyalty with B2C electric enterprise \\
\hline$\alpha 8$ & Behavioral loyalty with B2C electric enterprise \\
\hline$\alpha 9$ & The economic value from the third-party network platform \\
\hline$\alpha 10$ & The economic value from the third-party network platform \\
\hline$\alpha 11$ & The result quality of cooperation \\
\hline$\alpha 12$ & Social psychological risk \\
\hline
\end{tabular}

\subsection{Descriptive Analysis of Data}

The data was collected through issued in conference process, telephone interview, acquaintance questionnaire and network survey. We issued total of 1000 questionnaires, 300 copies issued in electronic business affairs meeting, recycling 249 copies; 400 questionnaires issued in website and recycling 360 copies; also, we recycling 100 questionnaires through acquaintance; in the shopping network distributed 400 questionnaires, recycling 360 copies. Finally, 910 questionnaires were collected, the questionnaires and recycling was shown in table 2.

Table 2. The Situation of Questionnaires Release and Recycling

\begin{tabular}{|l|l|l|l|}
\hline The way of questionnaire & Release quantity & $\begin{array}{l}\text { number of } \\
\text { recycling }\end{array}$ & $\begin{array}{l}\text { valid } \\
\text { questionnaires }\end{array}$ \\
\hline $\begin{array}{l}\text { Electric business } \\
\text { conference }\end{array}$ & 300 & 249 & 225 \\
\hline Telephone interview & 200 & 200 & 182 \\
\hline $\begin{array}{l}\text { Acquaintance } \\
\text { questionnaire }\end{array}$ & 100 & 100 & 95 \\
\hline Network survey & 400 & 360 & 283 \\
\hline Total & 1000 & 909 & 785 \\
\hline
\end{tabular}

\section{Empirical Analysis}

\subsection{Validity Analysis of Cooperation Performance}

To examine the validity of the sample data, draw a few index value: Chi square values $(\chi 2)$ is 150.75 , degree of freedom (df) is $98,(\chi 2 / \mathrm{df})$ is $1.536, \mathrm{P}$ value is 0.00051 , the approximate residual root mean square value is 0.062 , the specification of adaptation is 0.957, non standardized fitness index is 0.981, parsimonious fit indices is 0.792 simple criteria, comparison fit indices is 0.984 , incremental fit indices is 0.986 and relative fit indices is 0.947 . Standardization of RMS residual values is 0.046 , fit index is 0.868 , and adjusting the fit indices is 
0.821, parsimonious goodness of fit index is 0.630 . The following table control evaluation criteria, the display mode fit of belonging to a good level, therefore, the evaluation model is a consistent with empirical data models, the overall construct validity is high, can carry on the factor analysis. The result of Validity analysis was shown in table 3.

Table 3. The Validity Test of Each Factor

\begin{tabular}{|c|c|c|c|c|}
\hline Factor & $\begin{array}{l}\text { Evaluation } \\
\text { index }\end{array}$ & $\begin{array}{l}\text { corrected item- } \\
\text { total correlation }\end{array}$ & $\begin{array}{l}\text { Cronbach's } \\
\text { Alpha if item } \\
\text { deleted }\end{array}$ & $\begin{array}{l}\text { Cronbach 's } \\
\text { Alpha }\end{array}$ \\
\hline \multirow{4}{*}{$\alpha 1$} & A1 & 0.7624 & 0.8527 & \multirow{4}{*}{0.9132} \\
\hline & $\mathrm{A} 2$ & 0.8591 & 0.8860 & \\
\hline & A3 & 0.7756 & 0.8385 & \\
\hline & A4 & 0.7246 & 0.8571 & \\
\hline \multirow{3}{*}{$\alpha 2$} & A5 & 0.6762 & 0.7256 & \multirow{3}{*}{0.8692} \\
\hline & A6 & 0.7418 & 0.7920 & \\
\hline & A7 & 0.6750 & 0.7269 & \\
\hline \multirow{3}{*}{$\alpha 3$} & A8 & 0.7750 & 0.8232 & \multirow{3}{*}{0.8728} \\
\hline & A9 & 0.7942 & 0.8637 & \\
\hline & A10 & 0.7561 & 0.8356 & \\
\hline \multirow{4}{*}{$\alpha 4$} & A11 & 0.7952 & 0.8660 & \multirow{4}{*}{0.8295} \\
\hline & A12 & 0.8023 & 0.8531 & \\
\hline & A13 & 0.7726 & 0.8153 & \\
\hline & A14 & 0.7573 & 0.7962 & \\
\hline \multirow{3}{*}{$\alpha 5$} & $\mathrm{~B} 1$ & 0.7418 & 0.7830 & \multirow{3}{*}{0.7748} \\
\hline & $\mathrm{B} 2$ & 0.7016 & 0.7524 & \\
\hline & B3 & 0.6523 & 0.6952 & \\
\hline \multirow{3}{*}{$\alpha 6$} & B4 & 0.6218 & 0.6873 & \multirow{3}{*}{0.7628} \\
\hline & B5 & 0.7129 & 0.7932 & \\
\hline & B6 & 0.6056 & 0.6892 & \\
\hline \multirow{3}{*}{$\alpha 7$} & B7 & 0.7524 & 0.7861 & \multirow{3}{*}{0.8966} \\
\hline & B8 & 0.8013 & 0.8368 & \\
\hline & B9 & 0.8085 & 0.8562 & \\
\hline \multirow{3}{*}{$\alpha 8$} & B10 & 0.7883 & 0.8253 & \multirow{3}{*}{0.8125} \\
\hline & B11 & 0.7261 & 0.7642 & \\
\hline & B12 & 0.7456 & 0.8203 & \\
\hline \multirow{5}{*}{$\alpha 9$} & $\mathrm{C} 1$ & 0.7645 & 0.8203 & \multirow{5}{*}{0.8506} \\
\hline & $\mathrm{C} 2$ & 0.8129 & 0.8675 & \\
\hline & $\mathrm{C} 3$ & 0.7576 & 0.7824 & \\
\hline & $\mathrm{C} 4$ & 0.7203 & 0.7615 & \\
\hline & $\mathrm{C} 5$ & 0.6334 & 0.6908 & \\
\hline \multirow{4}{*}{$\alpha 10$} & C6 & 0.7405 & 0.7954 & \multirow{4}{*}{0.8472} \\
\hline & $\mathrm{C} 7$ & 0.6878 & 0.7362 & \\
\hline & $\mathrm{C} 8$ & 0.7216 & 0.7805 & \\
\hline & C9 & 0.6534 & 0.7239 & \\
\hline \multirow{3}{*}{$\alpha 11$} & D1 & 0.7061 & 0.7583 & \multirow{3}{*}{0.8241} \\
\hline & D2 & 0.7371 & 0.8124 & \\
\hline & D3 & 0.6532 & 0.6988 & \\
\hline \multirow{3}{*}{$\alpha 12$} & D4 & 0.5820 & 0.6709 & \multirow{3}{*}{0.7746} \\
\hline & D5 & 0.6572 & 0.7267 & \\
\hline & D6 & 0.6156 & 0.7032 & \\
\hline
\end{tabular}




\subsection{Confirmatory Factor Analysis}

(1) The factor variables of relationship perception are $\alpha 1, \alpha 2, \alpha 3, \alpha 4$. The correlation degree is high between these factors, and then we make second-order confirmatory factor analysis by using SPSS software, the result was shown in table 4.

Table 4. Second-order Confirmatory Factor Analysis for Relationship Perception

\begin{tabular}{|l|l|l|l|l|}
\hline Relationship & $\begin{array}{l}\text { UnStandardized } \\
\text { estimates }\end{array}$ & Stand.error & $\mathrm{t}$ & $\begin{array}{l}\text { Standardized } \\
\text { estimates }\end{array}$ \\
\hline$\alpha 1 \rightarrow \mathrm{A} 1$ & 1.442 & 0.101 & 9.842 & 0.88 \\
\hline$\alpha 1 \rightarrow \mathrm{A} 2$ & 1.461 & 0.096 & 15.261 & 0.92 \\
\hline$\alpha 1 \rightarrow \mathrm{A} 3$ & 1.125 & 0.089 & 12.596 & 0.83 \\
\hline$\alpha 1 \rightarrow \mathrm{A} 4$ & 1.263 & 0.110 & 11.215 & 0.78 \\
\hline$\alpha 2 \rightarrow \mathrm{A} 5$ & 1.088 & 0.100 & 10.047 & 0.77 \\
\hline$\alpha 2 \rightarrow \mathrm{A} 6$ & 1.056 & 0.110 & 9.686 & 0.82 \\
\hline$\alpha 2 \rightarrow \mathrm{A} 7$ & 1.012 & 0.110 & 9.492 & 0.80 \\
\hline$\alpha 3 \rightarrow \mathrm{A} 8$ & 0.956 & 0.100 & 9.294 & 0.79 \\
\hline$\alpha 3 \rightarrow \mathrm{A} 9$ & 1.307 & 0.126 & 10.531 & 0.79 \\
\hline$\alpha 3 \rightarrow \mathrm{A} 10$ & 1.521 & 0.160 & 9.762 & 0.80 \\
\hline$\alpha 4 \rightarrow \mathrm{A} 11$ & 1.258 & 0.110 & 11.184 & 0.89 \\
\hline$\alpha 4 \rightarrow \mathrm{A} 12$ & 1.204 & 0.120 & 9.956 & 0.81 \\
\hline$\alpha 4 \rightarrow \mathrm{A} 13$ & 1.186 & 0.124 & 10.032 & 0.78 \\
\hline$\alpha 4 \rightarrow \mathrm{A} 14$ & 1.125 & 0.117 & 9.738 & 0.81 \\
\hline
\end{tabular}

(2) The factor variables of relationship quality are $\alpha 5, \alpha 6, \alpha 7, \alpha 8$. The correlation degree is high between these factors, and then we make second-order confirmatory factor analysis by using SPSS software, the result was shown in table 5.

Table 5. Second-order Confirmatory Factor Analysis for Relationship Quality

\begin{tabular}{|l|l|l|l|l|}
\hline Relationship & $\begin{array}{l}\text { UnStandardized } \\
\text { estimates }\end{array}$ & Stand.error & $\mathrm{t}$ & $\begin{array}{l}\text { Standardized } \\
\text { estimates }\end{array}$ \\
\hline$\alpha 5 \rightarrow \mathrm{B} 1$ & 1.102 & 0.106 & 11.230 & 0.83 \\
\hline$\alpha 5 \rightarrow \mathrm{B} 2$ & 0.997 & 0.089 & 10.450 & 0.79 \\
\hline$\alpha 5 \rightarrow \mathrm{B} 3$ & 1.293 & 0.113 & 11.148 & 0.83 \\
\hline$\alpha 6 \rightarrow \mathrm{B} 4$ & 0.938 & 0.081 & 9.963 & 0.76 \\
\hline$\alpha 6 \rightarrow \mathrm{B} 5$ & 1.337 & 0.133 & 10.762 & 0.80 \\
\hline$\alpha 6 \rightarrow \mathrm{B} 6$ & 1.273 & 0.149 & 9.135 & 0.72 \\
\hline$\alpha 7 \rightarrow \mathrm{B} 7$ & 0.983 & 0.092 & 10.444 & 0.74 \\
\hline$\alpha 7 \rightarrow \mathrm{B} 8$ & 1.158 & 0.101 & 11.765 & 0.86 \\
\hline$\alpha 7 \rightarrow \mathrm{B} 9$ & 1.074 & 0.090 & 11.483 & 0.84 \\
\hline$\alpha 8 \rightarrow \mathrm{B} 10$ & 1.273 & 0.109 & 10.303 & 0.78 \\
\hline$\alpha 8 \rightarrow \mathrm{B} 11$ & 0.973 & 0.076 & 12.249 & 0.88 \\
\hline$\alpha 8 \rightarrow \mathrm{B} 12$ & 1.468 & 0.136 & 10.557 & 0.80 \\
\hline
\end{tabular}


(3) The factor variables of cooperation performance are $\alpha 9, \alpha 10$. The correlation degree is high between these factors, and then we make second-order confirmatory factor analysis by using SPSS software, the result was shown in table 6.

Table 6. Second-order Confirmatory Factor Analysis for Cooperation Performance

\begin{tabular}{|l|l|l|l|l|}
\hline Relationship & $\begin{array}{l}\text { UnStandardized } \\
\text { estimates }\end{array}$ & Stand.error & $\mathrm{t}$ & $\begin{array}{l}\text { Standardized } \\
\text { estimates }\end{array}$ \\
\hline$\alpha 9 \rightarrow \mathrm{C} 1$ & 1.189 & 0.106 & 11.230 & 0.83 \\
\hline$\alpha 9 \rightarrow \mathrm{C} 2$ & 0.935 & 0.089 & 10.450 & 0.79 \\
\hline$\alpha 9 \rightarrow \mathrm{C} 3$ & 1.261 & 0.113 & 11.148 & 0.82 \\
\hline$\alpha 9 \rightarrow \mathrm{C} 4$ & 0.808 & 0.081 & 9.963 & 0.76 \\
\hline$\alpha 9 \rightarrow \mathrm{C} 5$ & 1.432 & 0.133 & 10.762 & 0.80 \\
\hline$\alpha 10 \rightarrow \mathrm{C} 6$ & 1.365 & 0.149 & 9.135 & 0.72 \\
\hline$\alpha 10 \rightarrow \mathrm{C} 7$ & 0.754 & 0.066 & 11.358 & 0.85 \\
\hline$\alpha 10 \rightarrow \mathrm{C} 8$ & 0.595 & 0.059 & 10.153 & 0.79 \\
\hline$\alpha 10 \rightarrow \mathrm{C} 9$ & 0.989 & 0.089 & 11.069 & 0.83 \\
\hline$\alpha 10 \rightarrow \mathrm{C} 10$ & 0.956 & 0.090 & 10.762 & 0.80 \\
\hline
\end{tabular}

(4) The factor variables of external environment are $\alpha 11, \alpha 12$. The correlation degree is high between these factors, and then we make second-order confirmatory factor analysis by using SPSS software, the result was shown in table 7.

Table 7. Second-order Confirmatory Factor Analysis for External Environment

\begin{tabular}{|l|l|l|l|l|}
\hline Relationship & $\begin{array}{l}\text { UnStandardized } \\
\text { estimates }\end{array}$ & Stand.error & $\mathrm{t}$ & $\begin{array}{l}\text { Standardized } \\
\text { estimates }\end{array}$ \\
\hline$\alpha 11 \rightarrow \mathrm{D} 1$ & 1.102 & 0.986 & 11.122 & 0.83 \\
\hline$\alpha 11 \rightarrow \mathrm{D} 2$ & 0.965 & 0.109 & 10.729 & 0.80 \\
\hline$\alpha 11 \rightarrow \mathrm{D} 3$ & 1.183 & 0.013 & 11.023 & 0.82 \\
\hline$\alpha 12 \rightarrow \mathrm{D} 4$ & 0.890 & 0.081 & 9.963 & 0.79 \\
\hline$\alpha 12 \rightarrow \mathrm{D} 5$ & 1.384 & 0.113 & 10.101 & 0.81 \\
\hline$\alpha 12 \rightarrow \mathrm{D} 6$ & 1.065 & 0.121 & 9.135 & 0.72 \\
\hline
\end{tabular}

\subsection{Convergent Validity Inspection}

Through the result of the confirmatory factor for the factors in four dimensions analysis, the results showed that the standardized estimates were higher than the critical value as $0.45, \mathrm{t}$ values were significantly, and this shows that the construct reliability and content validity are standard, so the result can achieve the goal of the empirical research. Then we made the convergent validity test, as shown in table 8 . Through the convergent validity test, factor analysis and convergent validity test, the result shows that the model is qualified, so these data are valid and can be implemented to the further assumption and exploration, and we completed the empirical research by using subsequent regression.

Table 8. Result of Convergent Validity Test

\begin{tabular}{|l|l|l|l|l|}
\hline Latent variable & Factors & R2 & $\begin{array}{l}\text { composite } \\
\text { reliability }\end{array}$ & $\begin{array}{l}\text { average } \\
\text { variance } \\
\text { extracted }\end{array}$ \\
\hline Relationship & $\alpha 1$ & 0.68 & 0.814 & 0.642 \\
\hline
\end{tabular}




\begin{tabular}{|c|c|c|c|c|}
\hline \multirow[t]{3}{*}{ perception $\beta 1$} & $\alpha 2$ & 0.72 & & \\
\hline & $\alpha 3$ & 0.53 & & \\
\hline & $\alpha 4$ & 0.58 & & \\
\hline \multirow{4}{*}{$\begin{array}{l}\text { Relationship } \\
\text { perception } \beta 2\end{array}$} & $\alpha 5$ & 0.76 & \multirow{4}{*}{0.852} & \multirow{4}{*}{0.738} \\
\hline & $\alpha 6$ & 0.64 & & \\
\hline & $\alpha 7$ & 0.72 & & \\
\hline & $\alpha 8$ & 0.81 & & \\
\hline \multirow{2}{*}{$\begin{array}{l}\text { Cooperative } \\
\text { performance } \beta 3\end{array}$} & $\alpha 9$ & 0.87 & \multirow{2}{*}{0.886} & \multirow{2}{*}{0.695} \\
\hline & $\alpha 10$ & 0.52 & & \\
\hline \multirow{2}{*}{$\begin{array}{l}\text { External } \\
\text { environment } \beta 4\end{array}$} & $\alpha 11$ & 0.65 & \multirow{2}{*}{0.794} & \multirow{2}{*}{0.635} \\
\hline & $\alpha 12$ & 0.62 & & \\
\hline
\end{tabular}

\subsection{Regression Analysis on Cooperative Performance Model}

We made multiple linear regression analysis between cooperative performance and relationship quality, and try to find out the mediating effect of the relationship quality. Prior to the multivariate linear regression, we made average processing to all factors as cooperation performance, relationship cognitive and relationship quality. To analyze the mediating effect of relationship quality, we need to consider the internal relationship between hardware facilities, service quality, economic value and social value from the third-party network service.

(1) Intermediary effect of relationship quality between hardware facilities and cooperation performance

As cooperation performance includes economic value and social value, so we try to analyze the intermediary effect of relationship quality both in economic value and social value. Intermediary effect between hardware facilities and economic value can be show in table 9, and the equation of relationship quality (RQ), hardware facilities (HF) and economic value (EV) can be shown as:

$$
\begin{gathered}
E V=\alpha_{1} H F+\mu_{1} \\
E V=\alpha_{2} H F+\beta_{2} R Q+\mu_{2}
\end{gathered}
$$

Form table 9, we can get that the $\mathrm{T}$ test of hardware facilities is significantly, so the coefficient $\alpha 1$ is significant and we can proceed to the next step. In the step 2, we get that the $T$ test of relationship quality is 0 , so the coefficient $\beta 2$ is significant; and the $\mathrm{T}$ test of hardware facilities is 0.372 , so the coefficient $\alpha 2$ is not significant. The result means that the relationship quality has complete intermediary effect in the relationship between hardware facilities and the economic value of cooperation.

Table 9. Intermediary Effect between Hardware Facilities and Economic Value

\begin{tabular}{|l|l|l|l|l|l|l|}
\hline \multirow{2}{*}{ Model } & \multicolumn{2}{|l|}{ Non-Standardized Coef. } & Std. Coef. & \multirow{2}{*}{$\mathrm{t}$} & \multirow{2}{*}{ Sig. } \\
\cline { 3 - 7 } 1 & B & Std. Err. & Beta & & 0 \\
\hline \multirow{2}{*}{2} & Constant term & 2.389 & 0.457 & & 5.602 & 0 \\
\cline { 2 - 7 } 2 & Hardware facilities & 0.462 & 0.148 & 0.531 & 7.836 & 0 \\
\cline { 2 - 7 } & Constant term & 0.913 & 0.659 & & 2.582 & 0.016 \\
\cline { 2 - 6 } & $\begin{array}{l}\text { Relationship facilities } \\
\text { quality }\end{array}$ & 0.057 & 0.156 & -0.006 & 1.463 & 0.372 \\
\hline
\end{tabular}

Then, we analyze the intermediary effect of relationship quality between hardware facilities and social value, the result was show in table 10. The equation of 
relationship quality (RQ), hardware facilities (HF) and social value (SV) can be shown as:

$$
\begin{gathered}
S V=\alpha_{1} H F+\mu_{1} \\
S V=\alpha_{2} H F+\beta_{2} R Q+\mu_{2}
\end{gathered}
$$

Form table 10, we can get that the $\mathrm{T}$ test of hardware facilities is significantly, so the coefficient $\alpha 1$ is significant and we can proceed to the next step. In the step 2, we get that the $T$ test of relationship quality is 0 , so the coefficient $\beta 2$ is significant; and the $T$ test of hardware facilities is 0.042 , so the coefficient $\alpha 2$ is significant. The result means that the relationship quality has partial intermediary effect in the relationship between hardware facilities and the social value of cooperation.

\begin{tabular}{|c|c|c|c|c|c|c|}
\hline \multirow{2}{*}{\multicolumn{2}{|c|}{ Model }} & \multicolumn{2}{|c|}{ Non-Standardized Coef. } & \multirow{2}{*}{$\frac{\text { Std. Coef. }}{\text { Beta }}$} & \multirow{2}{*}{$\mathrm{t}$} & \multirow{2}{*}{ Sig. } \\
\hline & & B & Std. Err. & & & \\
\hline \multirow{2}{*}{1} & Constant term & 1.015 & 0.684 & & 1.649 & 0.164 \\
\hline & Hardware facilities & 0.764 & 0.125 & 0.510 & 6.251 & 0 \\
\hline \multirow{3}{*}{2} & Constant term & -0.673 & 0.703 & & -0.942 & 0.273 \\
\hline & Hardware facilities & 0.385 & 0.135 & 0.263 & 2.433 & 0.042 \\
\hline & $\begin{array}{l}\text { Relationship } \\
\text { quality }\end{array}$ & 0.712 & 0.167 & 0.396 & 5.157 & 0 \\
\hline
\end{tabular}

Table 10. Intermediary Effect between Hardware Facilities and Social Value

(2) Intermediary effect of relationship quality between service quality and cooperation performance

Then, we analyze the intermediary effect of relationship quality between service quality and cooperation performance. Intermediary effect between service quality and economic value can be show in table 11, and the equation of relationship quality $(\mathrm{RQ})$, service quality (SQ) and economic value (EV) can be shown as:

$$
\begin{gathered}
E V=\alpha_{1} S Q+\mu_{1} \\
E V=\alpha_{2} S Q+\beta_{2} R Q+\mu_{2}
\end{gathered}
$$

Form table 11, we can get that the $\mathrm{T}$ test of service quality is significantly, so the coefficient $\alpha 1$ is significant and we can proceed to the next step. In the step 2, we get that the $\mathrm{T}$ test of relationship quality is 0 , so the coefficient $\beta 2$ is significant; and the $T$ test of service quality is 0.004 , so the coefficient $\alpha 2$ is significant. The result means that the relationship quality has partial intermediary effect in the relationship between service quality and the economic value of cooperation.

Table 11. Intermediary Effect between Hardware Facilities and Economic Value

\begin{tabular}{|l|l|l|l|l|l|l|}
\hline \multirow{2}{*}{ Model } & \multicolumn{2}{|l|}{ Non-Standardized Coef. } & Std. Coef. & \multirow{2}{*}{$\mathrm{t}$} & \multirow{2}{*}{ Sig. } \\
\cline { 3 - 7 } & B & Std. Err. & Beta & & \\
\hline \multirow{2}{*}{1} & Constant term & 3.461 & 0.259 & & 9.628 & 0 \\
\cline { 2 - 7 } & Service quality & 0.376 & 0.048 & 0.491 & 5.651 & 0 \\
\hline \multirow{3}{*}{2} & Constant term & 1.102 & 0.370 & & 2.983 & 0.002 \\
\cline { 2 - 6 } & Service quality & 0.063 & 0.105 & 0.073 & 0.964 & 0.014 \\
\cline { 2 - 6 } & $\begin{array}{l}\text { Relationship } \\
\text { quality }\end{array}$ & 0.779 & 0.079 & 0.720 & 8.145 & 0 \\
\hline
\end{tabular}

Then, we analyze the intermediary effect of relationship quality between service quality and social value, the result was show in table 12 . The equation of 
relationship quality (RQ), service quality (SQ) and social value (SV) can be shown as:

$$
\begin{gathered}
S V=\alpha_{1} S Q+\mu_{1} \\
S V=\alpha_{2} S Q+\beta_{2} R Q+\mu_{2}
\end{gathered}
$$

Form table 12, we can get that the $\mathrm{T}$ test of service quality is significantly, so the coefficient $\alpha 1$ is significant and we can proceed to the next step. In the step 2, we get that the $\mathrm{T}$ test of relationship quality is 0 , so the coefficient $\beta 2$ is significant; and the $T$ test of service quality is 0.158 , so the coefficient $\alpha 2$ is not significant. The result means that the relationship quality has complete intermediary effect in the relationship between service quality and the social value of cooperation.

Table 12. Intermediary Effect between Hardware Facilities and Social Value

\begin{tabular}{|l|l|l|l|l|l|l|}
\hline \multirow{2}{*}{ Model } & \multicolumn{2}{|l|}{ Non-Standardized Coef. } & Std. Coef. & \multirow{2}{*}{ t } & \multirow{2}{*}{ Sig. } \\
\cline { 3 - 7 } \multicolumn{2}{|l}{1} & B & Std. Err. & Beta & & \\
\cline { 2 - 7 } & Senstant term & 2.435 & 0.582 & & 4.629 & 0 \\
\hline \multirow{3}{*}{2} & Constant term & 0.534 & 0.105 & 0.459 & 5.458 & 0 \\
\cline { 2 - 6 } & Service quality & 0.271 & 0.673 & & -0.462 & 0.036 \\
\cline { 2 - 6 } & $\begin{array}{l}\text { Relationship } \\
\text { quality }\end{array}$ & 0.165 & 0.114 & 0.138 & 1.454 & 0.158 \\
\hline
\end{tabular}

\section{Conclusions}

The current third-party network service in B2C business is not perfect in China, tourism enterprises frequent change the third-party platform because the cooperation risk. Most tourism enterprises are not clear whether third-party network platform will increase the economic and social value by cooperation. Also, the third-party platform is not effective to improve the business level, and do not know how to improve the service quality. Therefore, the third-party platform should pay more attention to the service quality and perceived value, grasp the collaborative operation of cognition, improve the cooperation performance by increasing relationship quality, and promote to establish a solid and long-term cooperation relationship. In this paper, we try to analyze the influence of relationship perception and relationship quality to the cooperative performance between tourism enterprises and the third-party platform. The result shows that the relationship quality has complete intermediary effect in the relationship between hardware facilities and the economic value, but has partial intermediary effect in the relationship between hardware facilities and the social value of cooperation. In addition, the relationship quality has complete intermediary effect in the relationship between hardware facilities and the social value of cooperation; but has partial intermediary effect in the relationship between service quality and the economic value.

We put forward the policy recommendations in the following aspects: (1) Strengthen service quality. Strengthen the close ties in the supply chain, and actively provide feedback path for each customer, guarantee the quality of service; (2) Improve the enterprise's core strength. Establish high-tech service system and adopt the new innovation technology, enable the international advanced organization and management experience of logistics facilities system; (3) Pay attention to personnel training. Regulate the industry practitioners, such as logistics specialist qualification examination; strengthen the cultivation of professional talents. 


\section{Acknowledgements}

The work of this paper is supported by National Social Science Youth Fund Project "Research on Rural Tourism Sustainable Development Strategy based on Urban-rural Integration" (No: 13CJY106); and the tourism industry in Anhui Province young expert training program (No: AHLYZJ201408).

\section{References}

[1] C. Mary and G. Desmond, "Annals of Tourism Research", vol. 35, no. 2, (2008), pp. 316-337.

[2] G. Saxena and I. Brian, "Annals of Tourism Research", vol. 35, no. 1, (2008), pp. 233-254.

[3] P. Nilsson, "Annals of Tourism Research, vol. 29, no. 1, (2002), pp. 7-24.

[4] C. Rozman, "Tourism Management", vol. 30, no. 5, (2009), pp. 629-637.

[5] R. Sharpley and J. Deborah, "Annals of Tourism Research, vol. 37, no. 2, (2010).

[6] C. Hunter and B. Kirsty, "Tourism Management, vol. 31, no. 6, (2010), pp. 754-758.

[7] G. Donald and C. Jack, "Tourism Management", vol. 21, no. 6, (2000), pp. 547-560.

[8] R. MacDonald and L. Jolliffe, "Annals of Tourism Research", vol. 30, no. 2, (2003), pp. 307-322.

[9] F. Isabelle, "Tourism Management”, vol. 26, no. 3, (2007), pp. 335-346.

[10] L. Molera, "Tourism Management", vol. 28, no. 3, (2007), pp. 757-767. 
International Journal of Security and Its Applications Vol.9, No.7 (2015) 